\title{
REPÚBLICA, DIREITOS E ORDEM GLOBAL
}

ROLF KUNTZ

A figura do Leviatã ficou no imaginário liberal como o Estado opressor que esmaga os indivíduos, sufoca a sociedade civil e faz tábula rasa dos direitos. Mero non sense, responderia Hobbes. Esse deus mortal, também chamado República (Commonwealth), ou Civitas em latim, é o que nos proporciona, em primeiro lugar, paz e defesa. Esse homem artificial tem a soberania como espírito, os magistrados e outros funcionários como articulações, a recompensa e o castigo como nervos, a riqueza e a prosperidade como força e a segurança do povo como função. Os conselheiros são a sua memória. A eqüidade e as leis, sua razão e sua vontade artificiais. Aconcórdia, a saúde. A sedição, a doença. A guerra civil, sua morte ${ }^{1}$. Sem a vontade e a força do Leviatã, não haveria lugar para a lavoura da terra, nem para uma vida industriosa, nem para o domínio da natureza, nem para a ciência, as artes e as letras. A vida do homem seria solitária, pobre, aborrecida, brutal e curta ${ }^{2}$. E os direitos? Mas que direito, responderia Hobbes, poderia ter o indivíduo, a não ser o de lutar por sua sobrevivência, num mundo em que todos poderiam tudo pretender, e em que ninguém seria menos vulnerável que qualquer outro?

É este aspecto, a vulnerabilidade, o atributo essencial da igualdade humana descrita no capítulo 13 do Leviatã. No limite, é o que nivela os indivíduos. É por esse fator que o problema básico da sobrevivência admite apenas uma solução perfeita: a vida política. $O$ recurso à força e à astúcia, meios individuais de luta, é apenas uma resposta precária, embora indispensável na ausência de um poder comum. A diferença entre as duas soluções é marcada com extrema nitidez na "regra geral da razão": buscar a paz, se houver esperança de alcançá-la, e, se não for possível obtê-la, usar todos os meios e vantagens da guerra ${ }^{3}$.

\footnotetext{
${ }^{1}$ HOBBES, Thomas. Leviathan, p. 9, Cambridge University Press, 1996.

2 Idem, p. 89.

3 Idem, p. 92.
} 
A argumentação hobbesiana estabelece o mais forte dos vínculos teóricos entre o Estado e o universo dos direitos - de todos aqueles direitos que só a lei pode tornar efetivos. Burke e Bentham, ao criticar a noção de direitos naturais que serviu de bandeira à Revolução Francesa, seguiram o caminho aberto pelo autor do Leviat $\tilde{a}^{4}$. Bentham adicionou à crítica uma severa análise da linguagem e nisso consistiu sua principal contribuição. Outras teses de Hobbes podem ter sido contestadas, com mais ou menos sucesso, nos três séculos e meio depois da publicação de sua obra mais importante. Mas a história dos direitos, no mundo moderno, praticamente se confunde com a história do Estado. A homenagem mais notável a essa tese talvez tenha sido prestada por Hanna Arendt, ao descrever o drama dos apátridas, no período entre as duas guerras mundiais. Sem nacionalidade, o apátrida não tinha vínculos com nenhum sistema de proteção de direitos. Sua única saída, em muitos casos, seria a prática de um pequeno crime, que o levaria de volta ao mundo jurídico. "Só como transgressor da lei", escreveu Hanna Arendt, "pode o apátrida ser protegido pela lei. Enquanto durar o julgamento e o pronunciamento de sua sentença, estará a salvo daquele domínio arbitrário da polícia contra o qual não existem advogados nem apelações" 5 .

O livro As Origens do Totalitarismo foi publicado em 1951. Três anos antes, a recém-criada Organização das Nações Unidas havia apresentado a Declaração Universal dos Direitos do Homem. Surgiriam novas declarações, protocolos e convenções, no meio século seguinte, para a promoção e a proteção de direitos os mais variados. Foram definidos crimes internacionais e concebidos mecanismos, também internacionais, para a proteção de certos direitos. A implementação dessas normas, no entanto, continuaria a depender principalmente do Estado. Se a história seguisse o curso imaginado pelos otimistas, o sistema global assumiria, gradualmente, as tarefas de criação e de proteção de direitos. Não foi o que ocorreu. As transformações da ordem mundial, no último quarto do século $\mathrm{XX}$, erodiram o poder do Estado e puseram em xeque, ao mesmo tempo, direitos principalmente sociais - consagrados no século e meio anterior.

Não é preciso, para reconhecer a importância dessas transformações, proclamar a morte do Estado e jogar no lixo da história o conceito

\footnotetext{
${ }^{4}$ BURKE, Edmund. Reflections on the Revolution in France, p. 149-154, Harmondsworth: Penguin Books, 1986. BENTHAM, Jeremy. Works, vol. II, p. 406-524, esp. 500-501, Bristol: Thoemmes Press, 1995.

${ }^{5}$ ARENDT, Hannah. The Origins of Totalitarianism, p. 286 e 292-296, N. York: Harvester Book, 1973.
} 
de soberania. Basta reconhecer que essas noções ganham novo sentido, com a reordenação do tabuleiro global. Essa reordenação envolve as dimensões econômica, política e militar. A terceira dimensão, que envolve o direito da guerra, o componente mais tradicional do Direito das Gentes, permite um acesso privilegiado ao exame dessas mudanças.

Um ponto de partida conveniente pode ser a invasão do Iraque, um evento que sublinha de forma dramática as mudanças na ordem global. A invasão foi liderada pelo governo dos Estados Unidos contra a opinião da maioria dos membros do Conselho de Segurança da ONU. Ao tomar essa iniciativa, o governo americano mostrou do modo mais explícito o que pode significar, para a ordem mundial, a condição singular de seu país. A consolidação de uma superpotência, incontrastável em força militar, econômica e tecnológica, é uma das novidades mais notáveis e mais perigosas para o sistema formado no pós-Segunda Guerra Mundial. A superpotência tem uma doutrina, hoje ostensiva, sobre como cuidar de seus interesses no plano internacional. Essa doutrina manifestou-se plenamente, perante o mundo, na segunda guerra contra o Iraque. Já estava em formulação, havia alguns anos, em centros de estudos de segurança nacional, em Washington. É dificil imaginar que alguém pudesse afirmar essa orientação com tanta clareza durante a Guerra Fria. Até o colapso da União Soviética, respeitou-se, como norma, a prática de apresentar cada ato de guerra como resposta a uma hostilidade iniciada pelo adversário. Continuou-se a venerar, pelo menos na aparência, a velha distinção entre agressão e retaliação, uma das bases das normas internacionais. Pode ter havido exceções, mas o padrão dominante foi claro durante séculos.

Não por acaso, o apoio do governo espanhol à política dos Estados Unidos, nesse episódio, foi criticado pelo professor Francisco J. Oroz num artigo intitulado "Aznar contra Vitória". Na segunda de suas Relectiones sobre os índios, dedicada ao "direito de guerra dos espanhóis contra os bárbaros", o dominicano Francisco Vitória, considerado por vários autores como o fundador do direito internacional, afirmou que só há uma causa para a guerra justa, a ofensa recebida. Esse critério foi consagrado no artigo 51 da Carta das Nações Unidas. Antes e depois da invasão do Iraque, especialistas debateram se um ataque preventivo seria uma violação desse preceito e se essa violação seria de alguma forma justificável. O debate continua aberto. Henry Kissinger admitiu, num artigo publicado em agosto de 2002, que os Estados Unidos poderiam, seguindo o caminho apontado pelo presidente George W. Bush, revolucionar duplamente o sistema internacional. Uma intervenção militar para mudança de 
um regime seria contrária ao sistema de Westfália, estabelecido em 1648. E um ataque preventivo seria contrário à lei internacional moderna, que só autoriza o uso da força em auto-defesa "contra ameaças atuais e não potenciais"6. Kissinger, no entanto, considerou que a ameaça de proliferação de armas de destruição em massa e a rejeição de um sistema eficiente de inspeção poderiam justificar aquela iniciativa. Mas não seria do interesse nacional americano, acrescentou, estabelecer o ataque preventivo como um princípio utilizável por qualquer nação.

O conceito de guerra preventiva, especialmente com a qualificação sugerida por Henry Kissinger, realça dois aspectos fundamentais do novo sistema global, ou, talvez mais precisamente, do sistema global em formação. Em primeiro lugar, explicita uma visão de mundo especial, própria de quem age em nome da única superpotência. Em segundo lugar, radicaliza a contestação da idéia de soberania. Acrescenta, portanto, uma dimensão dramática a uma tendência. Não a inaugura. Esta ressalva é importante para a análise da ordem que se vem constituindo há algumas décadas - e de forma bem perceptível pelo menos desde os anos oitenta. Esse processo envolve paradoxos aparentes que o analista político não pode simplesmente descartar, sob risco de jogar fora aspectos muito salientes e provavelmente relevantes da experiência. O mais importante, a longo prazo, talvez seja o da relação paradoxal, ao menos na aparência, entre democracia, soberania e sistema internacional.

O professor David Held ofereceu, nos anos noventa, uma contribuição especialmente relevante ao exame desse paradoxo e de suas conseqüências para a teoria democrática. Chamo a atenção, aqui, para dois trabalhos: 1) o ensaio "Democracy, the Nation-State and the Global System", publicado em 1991 no volume Political Theory Today; 2) o livro Democracy and the Global Order, de 1995, que apresenta bem mais amplamente as idéias propostas no outro texto.

Em termos simplificados, o paradoxo consiste no seguinte: no momento em que os valores democráticos alcançam um prestígio sem precedente na história, as condições de sua realização entram em pane. Em anos recentes, lembra David Held, um número crescente de nações passou a proclamar sua adesão aos princípios do governo do povo e às várias liberdades sacramentadas na tradição democrática. Ao mesmo tempo, no entanto, a democracia no Estado-nação independente se tornou insegura, na

${ }^{6}$ KISSINGER, Henry. "Preemptive Strike on Irak to Improve Peace Prospects", Washington Post, 11/8/2002. 
medida em que amplos setores de atividade foram progressivamente ordenados em nível global ${ }^{7}$. Essa transformação, pode-se acrescentar, continua em curso e cria problemas para os quais o pensamento político tradicional não dispõe de resposta. Até aqui, a democracia moderna foi concebida, em suas diversas variantes, como forma de organização do Estado nacional.

$\mathrm{Na}$ concepção tradicional, o governo democrático responde a cidadãos, que são detentores legais do poder, e produz decisões que afetam os habitantes de um território limitado. Toda relação extra-territorial entre esses três elementos é uma derivação desse esquema. As formas de organização democrática, admitidas certas variações num intervalo não muito amplo, obedecem a uns poucos padrões básicos: pessoas com direitos e obrigações essencialmente iguais determinam suas condições de vida por meio de mecanismos políticos. Seus direitos incluem a escolha dos governantes, que devem prestar contas de seus atos ao conjunto dos cidadãos. De modo geral, as decisões de interesse público devem refletir, direta ou indiretamente, a vontade da maioria - ou pelo menos da maioria das pessoas habilitadas a votar. Essa é a fórmula consagrada, ainda que a prática, muitas vezes, seja determinada por outros fatores.

Um pressuposto desse modelo é que as pessoas estejam integradas em unidades políticas separadas e independentes. Essas unidades podem comunicar-se, pacificamente, de acordo com normas que preservem a autonomia de cada uma. Essa autonomia corresponde, no plano legal, à soberania. É no âmbito do Estado soberano que os cidadãos, pela voz da maioria, manifestam suas preferências, determinam seu rumo coletivo e estabelecem o espaço de ação individual. A guerra é uma solução extrema para o acerto de diferenças entre as unidades independentes. É uma das manifestações da soberania.

Esse mecanismo se altera na medida em que as fronteiras se tornam permeáveis - ou mais permeáveis — a decisões tomadas no exterior. $\mathrm{O}$ que importa, para caracterizar a nova situação, é a incapacidade crescente do Estado, por seus processos interiores, de neutralizar os efeitos de fatores externos. Desde o início da era moderna, essa vulnerabilidade nunca foi tão ampla quanto hoje, em tempos de paz. Isto não quer dizer que as sociedades tenha vivido segregadas, nos últimos quatro ou cinco séculos, nem que tenham sido imunes ao impacto da economia internacional. Apenas para dar um exemplo: economistas se ocuparam, há muito tempo, do exame de como

7 HELD, David, "Democracy, the Nation-State and the Global System", In: HELD, D., ed., Political Theory Today, p. 197, Stanford University Press, 1991. 
se propagam as flutuações econômicas. A tese de mestrado de Roberto Campos, apresentada em 1947 à Universidade George Washington, foi dedicada a esse tema. É difícil ler esse trabalho, depois das crises dos anos 90, sem uma sensação de familiaridade. Haverá, portanto, alguma novidade no processo hoje rotulado como globalização? Se a palavra for usada apenas para indicar a intensificação das relações econômicas, estaremos falando de algo velho, talvez antigo. Mas não se trata apenas disso.

O cenário atual apresenta importantes diferenças quantitativas e qualitativas, quando comparado com o mundo conhecido até os anos sessenta ou stenta. Mudanças foram listadas por vários autores. $\mathrm{O}$ crime organizado, por exemplo, é muito mais complexo do que qualquer fenômeno aparentado que se tenha conhecido noutros tempos. $\mathrm{O}$ tráfico de drogas, o contrabando de armas e os mecanismos de lavagem de dinheiro compõem uma economia paralela que ultrapassa de longe, em complexidade e em sofisticação, os velhos esquemas da Máfia e de organizações semelhantes. Vínculos entre o crime organizado e associações políticas ilegais, como grupos guerrilheiros e redes terroristas mantêm permanentemente em xeque os sistemas nacionais de defesa do Estado e da ordem pública.

O terrorismo internacional é outra novidade relevante. Seu alcance, suas novas estratégias e sua organização forçam os governos à busca de respostas novas, porque os velhos sistemas de segurança nacional são ineficientes diante desse adversário. É inútil invadir outros Estados, em ações de retaliação ou de prevenção, quando o inimigo opera em rede, dispõe de ativos distribuídos pelo mundo e se articula como organização nãogovernamental.

Terrorismo e crime organizado em redes internacionais são duas novas dimensões da ilegalidade, que afetam a segurança dos Estados por vários processos que ultrapassam seus meios de controle. Mas no mundo legal também se multiplicam os desafios às formas tradicionais de organização política. "No nível internacional", segundo David Held, "ocorrem disjunções entre a idéia de Estado como em princípio capaz de determinar o próprio futuro e a economia mundial, as organizações internacionais, as instituições regionais e globais, a lei internacional e as alianças militares que operam para conformar e restringir as opções dos Estados-nações individuais"».

David Held relaciona quatro "disjunções" características do mundo atual. A primeira se refere às condições de operação da economia, que limitam a eficácia dos meios tradicionais da política econômica e, por-

\footnotetext{
8 Idem, pp. 212-22.
} 
tanto, da autoridade formal do Estado. Isso não quer dizer que as políticas fiscal e monetária tenham perdido utilidade, nem que as políticas de desenvolvimento se tenham tornado inócuas. Significa apenas que a integração cada vez mais estreita dos vários mercados sujeita as economias, cada vez mais amplamente, às conseqüências de decisões tomadas fora do território nacional. Nesse novo quadro, podemos acrescentar, direitos associados à regulação dos mercados - trabalhistas por exemplo - tendem a perder eficácia, porque se alteram as condições de proteção de seus detentores formais.

"A segunda grande área de disjunção entre a teoria do Estado soberano e o sistema global contemporâneo", explica David Held, "reside no vasto conjunto de regimes e de organizações internacionais que foram estabelecidos para administrar áreas inteiras de atividade transnacional (comércio, oceanos e espaço) e problemas coletivos de política." A influência desses regimes e organizações é variável e a obediência a suas normas e diretrizes não constitui, necessariamente, uma perda de soberania. Em muitos casos, a intervenção dessas instituições - o Fundo Monetário Internacional, por exemplo - ocorre por solicitação do governo interessado. Não obstante, acrescenta Held, há uma grande tensão entre a idéia de Estado soberano e a natureza das decisões em nível internacional. Essa tensão é especialmente forte no caso de associações, como a Comunidade Européia, com mandato para produzir leis que são impostas aos países membros. Held acrescenta, no entanto, uma importante ressalva: os poderes da Comunidade originaram-se de uma entrega voluntária de aspectos da soberania pelos países membros - uma decisão, segundo ele, que ajudou a sobrevivência da nação-estado européia, diante da dominância dos Estados Unidos nas três primeiras décadas do segundo pós-guerra e do crescente desafio econômico japonês.

A terceira disjunção opõe as normas internacionais, mesmo quando não sustentadas por instituições com poder coercitivo, às tradicionais condições de autonomia legal dos Estados. Pilares da velha ordem internacional, como a noção de que nenhum Estado é sujeito a jurisdição externa, vêm sendo ou erodidos por acordos negociados entre países ou simplesmente contestados por tribunais nacionais.

A disjunção número quatro se manifesta no contraste entre a velha idéia do Estado como unidade militar e estratégica independente e a existência de grandes potências e de grandes blocos de poder, como a Otan. Pertencer à Otan, segundo Held, não anula a soberania, mas qualifica-a de maneiras diferentes para cada Estado. Trata-se, no entanto, de uma forte "qualificação", por causa dos compromissos assumidos com a organização 
e das características da burocracia transgovernamental envolvida na operação e nas decisões da organização.

A Otan funcionou, no entanto, assim como o Pacto de Varsóvia, muito antes de se falar em globalização. As duas organizações são produtos da Guerra Fria e componentes fundamentais do esquema de poder bipolar que vigorou durante décadas. Durante a maior parte de sua história, até o colapso da União Soviética, os padrões da política econômica, no mundo capitalista, foram muito diferentes daqueles que se impuseram nas últimas duas décadas.

O cenário descrito por David Held é ainda um mundo formado por Estados soberanos, mas com menor autonomia de fato e com poderes legais erodidos. Ele não lamenta essa mudança nem propõe o retorno à velha situação. Registra a mudança, discute-a e propõe a construção de uma teoria democrática adequada a essas novas condições.

A erosão da soberania não resulta, no entanto, apenas de mudanças tecnológicas, econômicas, estratégicas e organizacionais que afetam objetivamente a chamada sociedade internacional. Essas mudanças têm sido acompanhadas de uma reavaliação da soberania como valor. Esse valor nunca foi aceito de forma incondicional, mas foi raramente contestado com eficácia a partir da segunda metade do século XVII. Antes disso, autores como Francisco Vitória e Roberto Bellarmino, embora admitindo o caráter sacrossanto do poder instituído, haviam definido condições que poderiam justificar a rebelião do povo e a intervenção estrangeira. Para isso, precisaram desenvolver uma argumentação complexa e habilidosa, que em grande parte refletia os interesses da Igreja de Roma. A contestação da soberania, hoje, é baseada em argumentos relativos a direitos humanos, à proteção do ambiente - classificada, muitas vezes, como um desses direitos —, à ajuda humanitária e até à reconstituição da soberania de Estados fracos. "Os ataques de 11 de setembro de 2001 lembraram-nos que Estados fracos podem ameaçar nossa segurança tanto quanto os fortes, provendo criadouros para o extremismo e abrigo para criminosos, traficantes de drogas e terroristas", disse numa conferência em janeiro de 2003 o então diretor de Planejamento de Políticas do Departamento de Estado americano, embaixador Richard Haass. "Em circunstâncias extraordinárias", disse ainda o diplomata, "quando um país chega ao colapso ou está despreparado para a independência formal, a comunidade mundial pode ter de assumir muitas das responsabilidades de um governo soberano." Timor e Kosovo são dois exemplos mencionados imediatamente e vinculados à ação da ONU e da Nato. No caso da Colômbia, a ação ameri- 
cana é descrita como ajuda no combate aos "narcoterroristas" - é esta a palavra usada - que ameaçam o funcionamento da sociedade.

No caso da invasão do Iraque, o argumento da segurança preencheu apenas parte da justificativa. A bandeira do combate a uma ditadura violenta foi também agitada, perante o público doméstico, no esforço do governo para legimitar a invasão. Externamente, o argumento principal foi mesmo o da ação preventiva contra um Estado agressivo e equipado com armas de destruição em massa. Este argumento pode ter sido mentiroso. O outro não vale uma discussão entre pessoas sérias. No entanto, as duas alegações contêm elementos presentes em várias tentativas de teorização sobre a justiça internacional. Mas por que teorizar sobre esse tipo de justiça? Porque os problemas do direito extravasam cada vez mais amplamente os limites do Estado. É por isso que David Held afirma ser necessário recriar a teoria democrática, situando a democracia não mais no âmbito do Estado-nação, mas no espaço internacional. É nesse espaço que os indivíduos devem atuar para o efetivo exercício de sua autonomia, isto é, para que possam de fato influir nas decisões que os afetam e construir as normas que dirijam sua vida.

Mas não basta para a construção teórica, ainda que meramente preliminar e exploratória, desenvolver um discurso acerca da justiça e de outros valores. De um modo vago, qualquer pessoa pode admitir que haja incompatibilidade, em certas circunstâncias, entre soberania e justiça. Quem se contentar com esse nível de percepção poderá satisfazer seus objetivos intelectuais e morais participando de passeatas contra tudo que parecer indesejável. Em Seattle, em 1999, os defensores do ar limpo e da preservação das florestas podiam defender o controle internacional da Amazônia e de outras grandes áreas florestais. Para esse propósito, é necessário desconsiderar fronteiras políticas. Outros manifestantes, no entanto, protestavam contra a Organização Mundial do Comércio por haver ordenado que o governo americano suspendesse restrições à importação de pescado de certos países. Essas barreiras haviam sido impostas com o pretexto de proteger tartarugas marinhas, supostamente ameaçadas por técnicas de pesca inadequadas. Um painel da OMC havia considerado a ação americana um mero artifício protecionista. Em Seattle, manifestantes fantasiados de tartarugas gritavam que a decisão daquele painel era uma violação da soberania americana e que o governo não deveria cumpri-la.

Algo mais sério é necessário, obviamente, para o estabelecimento de padrões internacionais de justiça dignos de respeito e dotados de alguma eficácia. Não basta, como observa Luigi Bonanate em seu livro 
Etica e Politica Internazionale, concluir que a produção e o tráfico de drogas, a devastação da floresta amazônica e a poluição da atmosfera com gás CFC afetam de forma indesejável as populações de muitos países. Qualquer intervenção baseada apenas nessas conclusões tenderá a resultar em violações pelo menos tão graves quanto os males que os interventores pretendam erradicar. A construção de um sistema de justiça internacional requer, segundo Bonanate, a aceitação de pelo menos cinco princípios: 1) superação da anarquia, isto é, da noção de que o sistema internacional seja formado de Estados indefectivelmente soberanos, que só se possam relacionar por meio de alianças ou de guerras; 2) renúncia tendencial ao uso da violência entre Estados; 3) pluralismo interestatal (nenhum Estado tem uma missão civilizadora ou emancipadora); 4) democratizaçao do sistema internacional, com aceitação de iguais prerrogativas, direitos e deveres para todos os Estados em relação aos cidadãos próprios e estrangeiros; 5) aceitação coletiva de princípios elementares de eqüidade, isto é, de respeito aos direitos dos indivíduos, independentemente de sua cidadania, com conseqüente abaixamento das fronteiras e livre circulação das pessoas ${ }^{9}$. Esse quadro envolve relações entre Estados, entre Estados e cidadãos próprios e de outros países e entre cidadãos de diferentes Estados. São esses princípios, uma vez aceitos e praticados, que podem permitir, segundo Bonanate, um adequado julgamento de quaisquer ações com as quais se pretenda promover a justiça internacionalmente.

Held vai um passo além dos princípios e esboça o desenho de uma federação democrática de Estados, com um papel especial para parlamentos regionais, no estilo do Parlamento Europeu, autorizados a produzir leis internacionais. $\mathrm{O}$ aspecto mais inovador da concepção, no entanto, é a possibilidade de referendos que envolvam eleitorados de vários países, definidos de acordo com os temas em discussão. Aparece, aqui, o tema da representatividade dos individuos e dos grupos civis nos sistemas normativos internacionais, uma das bandeiras agitadas, há alguns anos, por muitas ONGs.

Held e Bonanate, assim como Luigi Ferrajoli ${ }^{10}$, estão entre os autores que procuram dar um passo adiante na concepção de princípios e de instituições que permitam concretizar, num futuro ainda não determinado, um sistema de justiça internacional. É um campo de reflexão que se abre e que apenas começa a ser explorado. A ação política efetiva progride

\footnotetext{
9 BONANATE, Luigi. Etica e Politica Internazionale. pp. 204-06, Turim: Giulio Einaudi Editore, 1992.

10 FERRAJOLI, Luigi. A Soberania no Mundo Moderno. S. Paulo: Martins Fontes, 2002.
} 
muito mais lentamente e com resultados muito distantes do constitucionalismo internacional imaginado por Ferrajoli ou de qualquer das condições desenhadas por David Held ou Bonanate. Não só distantes, mas em certa medida opostos. A ação das grandes potências, no campo comercial, tem sido, com freqüência, a negação do multilateralismo. No campo da segurança, essa tendência vem-se acentuando com a consolidação dos Estados Unidos como única superpotência. Quanto à contestação da soberania, não passa, por enquanto, de um jogo com resultado pré-definido. Martin Jacques, pesquisador visitante da London School of Economics e ex-editor da revista Marxism Today, exibe uma visão pessimista dessa tendência. Aquela contestação, segundo ele, indicaria uma profunda mudança do pensamento, uma reversão de séculos de história, se o discurso tratasse do "círculo encantado do mundo desenvolvido - Grã-Bretanha, França, Estados Unidos e que tais". Mas a soberania em questão é a dos países do mundo em desenvolvimento, que na maior parte, até a segunda metade do século 20, não desfrutaram de soberania nenhuma. É deles, afinal, que se trata, quando se fala de terrorismo, de tráfico de drogas, de destruição de florestas e de segurança internacional. De que outros países poderia ser? Afinal, mesmo os exemplos citados por Bonanate, em sua discussão dos princípios de justiça e das condições de intervenção internacional, são na maior parte de países subdesenvolvidos ou em desenvolvimento. Simples coincidência?

ROLF KUNTZ é professor do Departamento de Filosofia da Universidade de São Paulo. 